\title{
Lo contable y la administración de lo público en el marco de la globalización
}

\author{
Diana Mórtigo Castro \\ Heidi Saray Guataquira \\ Cristian Yépes Lugo ${ }^{1}$
}

Mórtigo Castro, D., Saray Guataquira, H. \& Yépes Lugo, C. (2010). Lo contable y la administración de lo público en el marco de la globalización. Revista Activos, 14. 83-110.

Recibido: 15 de agosto de 2009 Aceptado: 15 de septiembre de 2009

\section{Resumen}

El proceso de globalización contable en lo público, hace referencia al rol que organismos como el Fondo Monetario Internacional y el Banco Mundial cumplen como promotores de una visión en la cual lo contable debe asegurar un sistema de representaciones de lo público acorde con los conceptos que promueven sobre lo que es de naturaleza pública y lo que no lo es. La necesidad de contar con cifras comparables para establecer esquemas de política pública y controlar con ellas la ejecución de las condicionalidades impuestas en sus créditos es la intención fundamental de dichas reglamentaciones; de esta manera, la forma de medir el déficit fiscal, el nivel de endeudamiento y el concepto de ingreso o gasto, determina las posibilidades de la política fiscal.

Palabras clave: globalización, intervencionismo, neoliberalismo, políticas públicas, Estado-nación, organismos financieros multilaterales, sistemas contables, representación contable, transacciones. 
ACTIVOS | REVISTA DE LA FaCULTAD DE CONTADURía PÚBlica

\begin{abstract}
Mórtigo Castro, D., Saray Guataquira, H. \& Yépes Lugo, C. (2010). The accountable thing and the administration of the public thing in the frame of the globalization. Activos Review, 14, 83-110.
\end{abstract}

\begin{abstract}
The process of countable globalization in the public themes, alludes to the roll that organisms as the International Monetary Fund and the World Bank fulfill like promoters of a vision in which the countable thing must assure a system of representations of the public thing according to the concepts that they promote on what is of public nature and what it is not. The need to be provided with comparable numbers to establish schemes of public politics and to control with them the execution of the conditionalities imposed in its credits is the fundamental intention of the above mentioned rules, like this, the way of measuring the fiscal deficit, the level of indebtedness and the concept of revenue or expense, they determine the possibilities of the fiscal policy.
\end{abstract}

Key words: Globalization, Interventionism, Neoliberalism, Public Politics, State Nation, Multilateral Financial Organisms, Countable Systems, Countable Representation, Deals.

Mórtigo Castro, D., Saray Guataquira, H. \& Yépes Lugo, C. (2010). Le comptable et l'administration du public dans le cadre de la globalisation, Revue Activos, 14, 83-110.

\title{
Résumé
}

Le processus de globalisation comptable dans le public, fait une référence au rôle que des organismes comme le Fonds monétaire international et la Banque mondiale expirent comme les promoteurs d'une vision dans laquelle le comptable doit assurer un système de représentations du public avec les concepts qu'ils provoquent sur ce qui est d'une nature publique et ce qui ne l'est pas. La nécessité de disposer des chiffres comparables pour établir des schémas de politique publique et pour contrôler avec celles-ci l'exécution des natures conventionnelles imposées de ses crédits est l'intention fondamentale des réglementations, de cette façon, la forme de mesurer le déficit fiscal,et le niveau d'endettement et le concept d'admission ou de dépense, ils déterminent les possibilités de la politique fiscale.

Mots clé: globalisation, l'Interventionnisme, le néolibéralisme, politiques publiques, l'État Nation, des organismes financiers multilatéraux, des systèmes comptables, une représentation comptable, des transactions. 


\section{Introducción}

Los cambios ocurridos en la estructura económica han modificado el papel que las agendas mundiales de naciones y entidades supranacionales vienen desempeñando. La crisis de los Estados de bienestar y la capacidad de los Estados para brindar respuesta y atención a las demandas sociales en un mundo más desigual, con mayores problemas de pobreza y con nuevos fenómenos como la violencia transnacional y la integración de mercados altamente divergentes, son algunos de los puntos más importantes en estos cambios.

Muchas de estas transformaciones vinieron de la mano de una política pública internacional que modificó las estructuras económicas y sociales, y las relaciones de poder entre los países. Ello es consecuencia también del surgimiento e implementación de una nueva ideología (el neoliberalismo), un modelo esencialmente económico que pone fin a lo que se consideró como "deficiencias" de los regímenes de Estados intervencionistas. El modelo neoliberal tiene sus raíces como modelo de política pública en el llamado "Consenso de Washington" y sus diferentes versiones, modelo que en la actualidad encuentra cabida en las agendas de política pública en el país, y aunque se haya verificado en la región un viraje político en la búsqueda de modelos alternativos, puede decirse que este viraje es aún insuficiente para crear un nuevo consenso alrededor de lo que debe ser la función del Estado y el replanteamiento de las dimensiones de lo público (Giraldo, 2003).

Toda política pública se piensa y se construye desde el ámbito político, es la sociedad la que a través de su voluntad elige democráticamente sus representantes. Aquellos profesionales idóneos, "jugadores" en el campo del poder que luchan por los diferentes intereses que demandan quienes confían en su labor, son los políticos (policy networks) que "elaboran" o adoptan desde lo impuesto en la agenda internacional la serie de políticas públicas que deben ser ejecutadas en el campo de la administración pública, la cual tiene la misión de implementarlas.Y en este escenario, la política pública no es sólo del interés estatal sino también de diferentes actores privados con poder político que de acuerdo a la visión propuesta por el modelo buscan simplemente la satisfacción de su propio beneficio (rent seekers).

El presente trabajo aborda los cambios que se han suscitado globalmente desde la perspectiva de la contabilidad pública en la construcción de sociedad. Para ello, se desarrollarán tres temas fundamentales: 1) principales transformaciones globales en la configuración del nuevo orden mundial; 2) el concepto de lo público y su relación con lo contable; y 3 ) lo público y el sistema de información contable tomando en consideración los elementos contenidos en el Manual de Estadísticas de Finanzas Públicas 2001. 


\section{Cambios globales en la configuración del nuevo orden mundial}

El primer elemento que aparece cuando se habla de la globalización es el debilitamiento de los Estados-nación y la cesión de soberanías que éstos hacen en beneficio de un orden supranacional.Los Estados nacionales pueden definirse como aquellos "aparatos políticos (...) con suprema jurisdicción sobre un área territorial delimitada, basados en el monopolio del poder coercitivo, y dotados de legitimidad como resultado de un nivel mínimo de apoyo o lealtad de sus ciudadanos" (Held, 1997, p. 71). Sobre estos aparatos la globalización ha generado enormes transformaciones.

En este sentido, uno de los cambios más significativos en el contexto de las reformas económicas de los años ochenta y noventa ha sido la proyección del capital financiero por fuera de las fronteras territoriales de los Estados nacionales; por tanto, el principio de territorialidad se ve alterado en la medida en que las fronteras son poco exactas cuando de la expansión del capital se trata.

El Estado pierde entonces el poder y el privilegio de orientar las políticas públicas, ya que los nuevos actores transnacionales que confluyen en su territorio toman decisiones que fundamentalmente favorecen sus intereses y afectan el destino de la nación en general. Esta situación lleva a un inexorable proceso de deslegitimación del Estado frente a la sociedad, dado que la política pública prioriza el beneficio empresarial privado, en detrimento del interés común o interés público.

Dicho cambio implica además la proyección del Estado en un ámbito supranacional, cuyo objetivo principal es desarrollar capacidades para responder a las nuevas dinámicas del capital transnacional. Esto implica además nuevas formas de distribuir el poder en el territorio ${ }^{2}$, promulgadas por políticas de descentralización y desregulación estatal.

Por otra parte, en el plano económico se plantea la idea de un Estado de intervención mínima, es decir, un Estado en donde prevalece la lógica del individualismo y el beneficio particular, además de un respeto por las reglas de distribución del mercado. Hay aquí una nueva tendencia en donde "el sector público no sólo se retira de la actividad productiva directa (...) sino que cuestiona además su responsabilidad para satisfacer los derechos reconocidos" (Roll, 1999, p. 243).

2 Como en el caso de la desconcentración y la delegación de las funciones de la administración central, las cuales denotan una repartición del poder. 
Estos principios se oponen a los planteados por los países latinoamericanos que desde la segunda posguerra venían implementando el llamado modelo de sustitución de importaciones (MSI), cuya esencia radica en el intervencionismo estatal, con un énfasis en la obtención del pleno empleo y del efecto multiplicador mediante el impulso a la demanda, la protección a la industria nacional y la promoción de la misma en el exterior. Hay que señalar que, asimismo, el MSI implica un Estado paternalista, el cual asume la responsabilidad directa por la garantía de la oferta de la seguridad social y plantea la política pública a partir del enfoque de subsidios a la oferta en el cual “... se ayuda a los productores por medio de un subsidio monetario o de otra índole con la esperanza de que baje el costo del bien o servicio y así se haga más accesible a los usuarios” (Berry, 2004, p. 39).

La globalización, tal como la conocemos actualmente, tiene sus orígenes en la crisis económica que se presenta en los países industriales en los años setenta, la cual llevó al planteamiento de nuevas alternativas económicas que enfrentaran los agudos procesos de hiperinflación que caracterizaron la crisis. Es aquí cuando se da inicio al modelo neoliberal o modelo de ajuste estructural que buscaba reactivar la economía basándose en el dinamismo del mercado, lo cual implicaba el logro de la expansión y conquista de nuevos mercados para la generación de oportunidades de ganancia dentro de un nuevo orden mundial.

El modelo neoliberal no constituye una ordenada corriente de doctrinas, sino que en su construcción se superponen como mínimo dos vertientes fundamentales (Bautista, 2008):

1. El liberalismo radical (cuyos principales exponentes son F. V. Hayek y A. V Mises), el cual defiende un Estado mínimo, cuya función es básicamente garantizar la seguridad y el intercambio mercantil. Es en otros términos lo que se denomina el "Estado gendarme".

2. El liberalismo social (cuyos principales ideólogos son J. Rawls y A. Sen), el cual propone que el punto central de la intervención del Estado gire alrededor de los problemas de la justicia y la naturaleza de la pobreza. Pero esta justicia se basa en la aceptación de la desigualdad y en la intervención sobre la misma solamente cuando es moralmente deseable por parte de la sociedad (Rawls, 2001). Ante la inevitabilidad de la desigualdad debe optarse por una justicia equitativa con un trato diferencial más acorde a los dictámenes del mercado, que premie el esfuerzo y los resultados de la eficiencia en el uso de los recursos. El Estado asume este criterio moral para "incluir" a los "excluidos" (pobres) y los dota de unos mínimos de capital humano para que entren a jugar como agentes en el mercado y compitan. Este es el discurso social del modelo neoliberal. 
ACTIVOS | REVISTA DE LA FaCUlTAD DE CONTADURÍa PÚblica

La crisis de los países industrializados se replicó con otras condiciones en los países latinoamericanos: en la región, la crisis fue fundamentalmente un problema del desequilibrio en el financiamiento de las finanzas públicas, y un sobreendeudamiento externo que se hizo impagable en 1982, cuando todos los países de la región (excepto Colombia) cesaron el pago de sus deudas. El impacto de esta crisis llevó con urgencia a realizar un ajuste fiscal, que fue asumido por los gobiernos latinoamericanos, los cuales se vieron en la obligación de sacrificar el gasto público, recurriendo a fuertes planes de choque para controlar la hiperinflación que resultó del abuso de la emisión para tratar de sostener la dinámica de gasto público. La recesión, el congelamiento del aparato productivo y el aumento del desempleo llevaron a una drástica caída de los ingresos públicos entre 1984 y 1988 (CEPAL, 1998).

Los ajustes fiscales que se hicieron bajo el monitoreo del Banco Mundial (que financió el programa de reformas macroeconómicas) y el FMI (que actuó en realidad como garante del club de acreedores) introdujeron los principios del modelo neoliberal y prepararon las estructuras económicas para su brusco paso del modelo de protección interna, a uno de intensa competencia externa. En este contexto, el papel de la política pública es el de encargarse de validar el modelo de competitividad y dispersar el efecto adverso que la precarización de las formas de vida producidas por el ajuste fiscal a favor de la deuda, y los sacrificios que exige la competitividad vía salarios, imponen sobre la clase trabajadora, a través del diseño de complejos aparatos de subsidios residuales que se focalizan en los denominados "pobres" (Giraldo, 2006).

Así, el estilo de la globalización impuesta en América Latina buscó desde el inicio garantizar un determinado paquete de políticas públicas orientadas por el afán de flexibilizar los regímenes de los sistemas de seguridad social, reducir el precio de la mano de obra y abrir las fronteras al acceso tanto de la inversión extranjera directa como de la inversión de portafolio, con pocos condicionamientos sobre sus aportes al desarrollo nacional y modificando las estructuras económicas para maximizar el valor del aporte del retorno de estas inversiones.

El fin de la Guerra Fría en los finales de la década de los ochenta y los principios de los noventa significó una importante coyuntura agilizadora de los procesos de globalización. Allí se genera una nueva dinámica mundial debido al derrumbe del comunismo, que constituye un refuerzo político para introducir cambios ideológicos en el campo político y especialmente en el campo de las políticas públicas. Una vez vencido el comunismo, estaban las condiciones dadas para hablar del "fin de la historia" y para declarar el modelo 
capitalista basado en la expansión del capital financiero como la única lógica posible y viable para el desarrollo económico y social.

Este proceso de globalización encuentra un significativo apoyo en el auge del desarrollo de nuevas tecnologías. Son éstas las que van a determinar factores como el de la seguridad nacional y el desarrollo de nuevas industrias a nivel mundial. Por esta razón, se financiaron investigaciones para la industria armamentista en respuesta a un orden mundial propio del realismo pragmático y luego consolidado con la doctrina de la guerra preventiva, que tiene su primer paso en la llamada "guerra de las galaxias" ${ }^{3}$ que luego se intensificará en los tiempos de la lucha contra el terrorismo. A su vez, el impulso de las telecomunicaciones generó el acortamiento de las distancias sin distinción de nacionalidades forjando un mundo más pequeño, en donde las grandes industrias encontraron las mejores oportunidades para realizar sus grandes inversiones, pero especialmente las tecnologías de manejo de sistemas de información masivos, que abrieron el frente para el desarrollo de una inmensa serie de productos y servicios que ayudaron a la deslocalización de la inversión y de las relaciones laborales, así como a la creación de un universo gigante de instrumentos financieros.

Es a partir de ello que la globalización es entendida como la acentuación de los intercambios de diversa índole ${ }^{4}$ que se materializan en los diferentes procesos de integración económica, dando así vía libre a la acentuada circulación de los flujos (comerciales y en especial financieros) entre los diferentes Estados. Sin embargo, lo que realmente evidencia este fenómeno de la globalización es el aparente triunfo del capitalismo. Como lo afirma Touraine (2005, p. 14): “... este proceso de globalización es que la economía, o la mayor parte de los sectores económicos, se organizan y siguen una lógica a nivel mundial ...”.

De esta manera, se muestra una permeabilidad en los campos políticos, sociales y culturales a favor de las dinámicas del capital y especialmente del capital financiero, el cual gana un peso muy importante en la determinación de los flujos económicos alrededor del mundo.

En resumen, la diversidad de cambios por los cuales atraviesa el mundo de hoy evidencia una profunda transformación y reconfiguración de los lineamientos que orientaban la actuación y los objetivos del Estado-nación en su relación con el mundo en los campos político, económico, social y cultural. Éstos implican concesiones importantes en el sistema

En el entorno se presentan enfrentamientos constantes y se percibe una actitud de guerra, de allí que se tome como referencia al estado de naturaleza. Véase el caso norteamericano en su carrera armamentista.

Bienes y servicios, personas, información, culturas, etc. 
ACTIVOS | REVISTA DE LA FaCUlTAD DE CONTADURÍa PÚblica

de políticas públicas, y fundamentalmente la eliminación de las barreras al capital, el paso a un mundo político en el cual la determinación de las políticas viene fundamentalmente de la mano de las instituciones financieras multinacionales dominadas políticamente por los Estados Unidos (BM, FMI, BID), y un auge de las telecomunicaciones y el manejo de cantidades inmensas de información que transforman profundamente los sistemas productivos y especialmente las relaciones laborales, las cuales son el objetivo principal (junto con las inmensas fuentes de negocios provistas por el Estado).

\section{La globalización y sus efectos sobre las políticas públicas en América Latina}

Aunque la globalización afecte de una manera específica e instaure diferentes tendencias en los campos anteriormente nombrados, el económico ha sido el campo más significativo de transformación. En este sentido, se observa una construcción de agendas que favorecen las decisiones económicas proclives a la libertad de los mercados, al igual que el establecimiento de pactos internacionales que faciliten la libre movilidad del capital. A su vez, en el ámbito cultural la fuerte influencia de los mass media moldea y crea nuevos prototipos que estimulan el consumo, homogeneizando identidades y creando nuevas necesidades cuya satisfacción se encuentra en los nuevos mercados que consolida el capitalismo. Reformas económicas y alienación cultural constituyen solamente dos caras de la misma moneda.

En el caso latinoamericano, las políticas económicas del Estado de intervención en el MSI se transforman en políticas de Estados regulacionistas y gendarmes en el modelo neoliberal (Banco Mundial, 1995). En esta medida, la política económica aplicada en Latinoamérica desconoció preceptos fundamentales de la teoría keynesiana. La política de subsidios también se modifica, pasando de beneficiar a la oferta a favorecer a la demanda, promoviéndose así la competencia entre los productores y a su vez la "libertad" de elección por parte de los "ciudadanos-clientes".

Sumado a lo anterior, buena parte de las reformas recaen sobre el aparato administrativo del Estado. Según Vargas, “....este modelo [intervencionista] de Estado evidencia su agotamiento y entra en crisis, evidenciando sus debilidades: la excesiva burocratización, corrupción e ineficiencia del aparato administrativo que ejerce un presupuesto deficitario e inestabilidad macroeconómica" (Vargas, 2004,p. 19); de allí que la Administración Pública y todos los sistemas de información que apoyan la toma de decisiones y los sistemas de control tengan que reformarse. Se pasa de una administración que trabaja por procesos, a 
una que trabaja por resultados, con un cambio enorme en los sistemas de incentivos y la creación (al menos en apariencia) de un sistema burocrático mucho más técnico y menos dependiente de las influencias políticas que de sus propios resultados.

En la política social, hay que señalar que se dirige principalmente hacia la reducción de la pobreza (a la que identifican como el mal mayor de la economía) a través de la aceleración del crecimiento económico, el cual solamente puede obtenerse con la implementación de políticas de libre mercado, que favorezcan la eficiencia asignativa.

Un segundo punto de la política social es que el Estado presta servicios únicamente a la población más vulnerable, según el principio de focalización. Para ello, recurren a un doble argumento: las restricciones fiscales a las que se hallan sometidos los gobiernos por causa de la crisis de la deuda y que implicaban serios problemas para la financiación de programas universales, como también una nueva visión sobre la justicia distributiva, la cual comentamos con anterioridad.

Un tercer punto es la opción de que el sector privado se encargue de la prestación de algunos servicios como la educación, la salud y las pensiones, y aquí se constituye una buena parte del discurso de lo público en el modelo neoliberal. Ya que el Estado es corrupto y la corrupción implica un uso privado de recursos públicos, es posible que las entidades privadas en términos de eficacia y eficiencia hagan un mejor servicio a lo público, entendido como el interés de todos. Así, una escuela privada, al ser más eficiente que una pública en el uso de recursos, hará un mejor servicio a lo público al ahorrar cuantiosos recursos y evitar que éstos sean capturados por los grupos de interés que siempre aparecen en los procesos políticos que asignan recursos del Estado (como los sindicatos de maestros, por ejemplo).

Puede afirmarse entonces que Latinoamérica sufre un proceso de inserción en el fenómeno de la globalización de forma subordinada a la política del Consenso de Washington, el cual prescribe "la liberalización comercial y financiera, la privatización de las empresas estatales, presupuestos balanceados, tasas de cambios fijas, etc., como base para el crecimiento económico" (Vargas, 2004, p. 19). Con lo cual se abre la puerta al ciclo de endeudamiento externo excesivo, el cual a partir de los años noventa será también endeudamiento interno. Las reformas del Consenso de Washington pueden condensarse en tres frentes comunes: liberación de mercados, políticas públicas y límites al mercado. Lo anterior se observa de manera más detallada en las siguientes tablas: 
ACTIVOS | REVISTA DE LA FACULTAD DE CONTADURía PÚblica

Tabla 1. Consenso de Washington (presentación orgánica)

\begin{tabular}{|l|l|l|}
\hline $\begin{array}{l}\text { Nivel 1 } \\
\text { Liberación de mercados }\end{array}$ & $\begin{array}{l}\text { Nivel 2 } \\
\text { Políticas públicas }\end{array}$ & $\begin{array}{l}\text { Nivel 3 } \\
\text { Límites al mercado }\end{array}$ \\
\hline 1.1 Mercado de bienes: & 2.1 Disciplina fiscal & $\begin{array}{l}\text { 3.1 Banco Central inde- } \\
\text { pendiente }\end{array}$ \\
- Apertura comercial & $\begin{array}{l}\text { 2.2 Focalización del gasto } \\
\text { Subsidio a la demanda }\end{array}$ & $\begin{array}{l}3.2 \text { Sistema presupuestal } \\
\text { jerarquizado (presupues- } \\
\text { to público determinado } \\
\text { por autoridad fiscal sin } \\
\text { injerencia de órganos de } \\
\text { representación popular u } \\
\text { otro órgano político) }\end{array}$ \\
- Apertura de capitales & 2.3 Impuestos neutrales \\
- Desregulación financiera & 2.5 Descentralización fiscal \\
1.3 Mercado laboral & $\begin{array}{l}\text { 3.3 Sistema judicial inde- } \\
\text { pendiente y fuerte }\end{array}$ \\
\hline
\end{tabular}

Fuente: Giraldo (2008).

De otra parte, los cambios que operan sobre la estructura de las políticas públicas son considerables, si se comparan con los instaurados durante la vigencia del estado de intervención. La Tabla 2 ilustra las dimensiones de estos cambios.

Tabla 2. Comparación de los modelos cepalino (MSI) y de ajuste estructural

(Consenso de Washington)

\begin{tabular}{|l|l|}
\hline $\begin{array}{l}\text { Modelo “Consenso de Washington” } \\
\text { (Modelo de apertura económica) }\end{array}$ & $\begin{array}{l}\text { Modelo CEPAL } \\
\text { (Modelo de sustitución de importaciones) }\end{array}$ \\
\hline \multicolumn{2}{|c|}{ Régimen fiscal - Financiero } \\
\hline $\begin{array}{l}\text { Gobierno financia su déficit contratando } \\
\text { deuda en el mercado de capitales }\end{array}$ & $\begin{array}{l}\text { Gobierno financia su déficit con crédito del } \\
\text { Banco Central (emisión monetaria) }\end{array}$ \\
\hline $\begin{array}{l}\text { Seguridad Social a intermediación } \\
\text { financiera privada }\end{array}$ & Seguridad social estatal \\
\hline Mercado libre de divisas & Control de cambios \\
\hline Desregulación financiera & Sistema financiero regulado \\
\hline Libre inversión extranjera & Control a la inversión extranjera \\
\hline
\end{tabular}




\begin{tabular}{|l|l|}
\hline \multicolumn{2}{|c|}{ Cambios institucionales } \\
\hline $\begin{array}{l}\text { Banco Central independiente del } \\
\text { gobierno }\end{array}$ & Banco Central controlado por el gobierno \\
\hline $\begin{array}{l}\text { Gobierno Nacional se concentra en } \\
\text { defensa y justicia }\end{array}$ & $\begin{array}{l}\text { Gobierno Nacional, además de defensa } \\
\text { y justicia, asume gastos sociales y } \\
\text { construcción de infraestructura básica }\end{array}$ \\
\hline Descentralización política y fiscal & Centralismo \\
\hline $\begin{array}{l}\text { Agencias descentralizadas } \\
\text { (establecimientos públicos) se financian } \\
\text { vendiendo servicios }\end{array}$ & $\begin{array}{l}\text { Agencias descentralizadas se financian con } \\
\text { transferencias gubernamentales }\end{array}$ \\
\hline Privatización & Estatización \\
\hline $\begin{array}{l}\text { Manejo fiscal en función del ajuste } \\
\text { económico }\end{array}$ & $\begin{array}{l}\text { Manejo fiscal en función de la reactivación } \\
\text { económica }\end{array}$ \\
\hline Subsidios a la demanda & Subsidios a la oferta \\
\hline Impuesto sobre consumo & Impuestos sobre renta y patrimonio \\
\hline Apertura comercial & Proteccionismo \\
\hline Flexibilización laboral & Proteccionismo laboral \\
\hline
\end{tabular}

Fuente: Giraldo (2008).

De acuerdo con Giraldo (2003, p. 18):

...en la región se ha venido adoptando una serie de reformas que llevan a un nuevo marco de regulación y una redefinición de las instituciones políticas y económicas (...). Esa regulación se basa en la flexibilización de los mercados (bienes, capitales, laboral), en cambios de las formas de intervención del Estado, dejando un mayor juego a los mercados y en el traslado de la regulación monetaria a un banco central independiente, $\mathrm{y}$ últimamente se ha insistido en un autoridad fiscal independiente.

Una parte fundamental de los cambios que ocurren en la esfera económica en el nuevo paradigma económico es la promoción de la política de descentralización que tiene como fin garantizar una mayor competitividad entre las regiones como medio para incentivar el desarrollo económico y lograr un efectivo acercamiento entre el Estado y los ciudadanos. El fundamento de este proceso es que, bajo el principio de subsidiariedad en donde el servicio 
ACTIVOS | REVISTA DE LA FaCULTAD DE CONTADURía PÚBlica

es suministrado por el nivel inferior del gobierno que debe proveerlo y financiarlo bajo las dinámicas del mercado (por medio de la venta de bienes y/o servicios) ${ }^{5}$, se logre una redistribución más adecuada de los recursos del gasto público: las empresas del Estado dejan de financiarse por la vía del presupuesto y comienzan a financiarse mediante la venta de servicios y bienes en el mercado. Esto se supone que incentiva la competitividad económica, a la vez que aliviana la carga fiscal de la nación, pero implica una reorientación de los objetivos de la administración del Estado y fundamentalmente un cambio en el rol de los administradores públicos, quienes ahora toman sus decisiones basadas más que en el cumplimiento de políticas, en el incentivo de la obtención de ganancias en los frentes de "negocio" que operan.

La otra parte del argumento sobre la descentralización es que dicho proceso hace más cercano el Estado a los ciudadanos, los cuales están incentivados a ejercer un control efectivo de la gestión de los recursos públicos. Son ellos quienes observarán si los recursos públicos son asignados eficientemente y si satisfacen sus necesidades básicas. En este sentido, el modelo parece indicar que son los mismos ciudadanos quienes participan activamente en la formulación de la política social.

Pero en el fondo la descentralización es un proceso que traslada la ejecución del gasto a los gobiernos subnacionales. Se hace necesario que el gobierno central les realice transferencias de recursos, ya que son estos los que ejecutan el gasto público (transferencias horizontales) y también se transfieren recursos para financiar los niveles de la administración pública (transferencias verticales).

Pero fundamentalmente, como señala Giraldo (2008), la descentralización es una forma de llegar a la privatización: en el momento en que las unidades de prestación de servicios públicos (salud: hospital; educación: escuelas) dejan de depender del presupuesto nacional, para autofinanciarse vendiendo servicios en el mercado, opera en ellas un cambio en su racionalidad económica, aplicando el principio de exclusión a quienes no tienen ingresos para pagarse el servicio al que desean acceder. Al actuar las empresas y entidades públicas como empresas privadas se da paso a un proceso intensivo de privatización que transforma radicalmente el actuar de la gestión pública, la cual debe reorientar sus sistemas de información y control a la nueva racionalidad con la que funciona la administración del Estado.

5 Sin embargo, en dicho principio no pueden incluirse todos los bienes, solamente a los que se les identifican beneficiarios directos. Es decir, son bienes y servicios privatizables que resuelven una necesidad directa y específica de algún sector de la sociedad (los más pobres) de manera temporal para que no se incurra en la distorsión del gasto. 
Cuando el Estado prioriza el beneficio empresarial privado en detrimento de la población en general, las oportunidades laborales, la prestación de servicios, la regulación salarial, entre otros aspectos sociales, se ven cobijados bajo la racionalidad privada que busca la disminución efectiva de costos y la maximización del ingreso y deja de lado el beneficio social potencial. Aunque hablar del beneficio social o el impacto social siga siendo algo nebuloso y poco tangible en el actual contexto de la contabilidad en Colombia, es necesario señalar que los indicadores de medición del impacto social y el beneficio social no son un tema nuevo en la disciplina contable y cuentan por lo menos con cuatro décadas de desarrollo conceptual.

\section{El concepto de lo público, la democracia y su relación con lo contable}

La forma como se entiende lo público en la definición y aplicación del modelo económico constituye un factor trascendental, en la medida en que con ello se estructura una perspectiva de los objetivos de desarrollo que busca la sociedad. En la búsqueda de una perspectiva de lo público que permita configurar una sociedad incluyente, es necesario entender el ámbito de lo público/privado como "un campo de la producción de una disposición relacional estructurante-estructurada que configura una variedad de órdenes, distancias, centramientos y fuerzas de lo visible- no visible, admisible-no admisible, enunciable-no enunciable, y accesible-no accesible" (Lozano, 2005, p. 7).

Esta dualidad de lo público invita a reflexionar acerca de los cambios presentados en la esfera de lo público a la luz de las transformaciones del Estado-nación, en donde "lo público" se ve reducido a lo meramente relacionado con aquello que emana exclusivamente del aparato estatal. Se desconoce, por tanto, la multiplicidad de factores que implican la configuración de la totalidad de una esfera pública, que involucre un conjunto más amplio de la sociedad, la cual debe hacer parte activa en el proceso de toma de decisiones políticas en el marco de un verdadero sistema democrático; "se amplía lo público al hacer visibles las preocupaciones de actores que de otro modo no se notarían, al tender los límites del reconocimiento de los otros" (Santos, 2002). Lo anterior implica que se diseña un tipo de público en donde existen unos actores visibles incluidos en el debate público y otros fuera de él, actores que por tanto serán subordinados y condicionados.

Las concepciones que se han generado en la historia sobre lo público han mutado y son el resultado de unas experiencias históricas. Parte de su cambio ha sido influenciado por las 
ACTIVOS | REVISTA DE LA FaCUlTAD DE CONTADURÍa PÚblica

concepciones económicas que rodean tales concepciones, por las concepciones alrededor de lo privado y por la idea misma de democracia. Por ejemplo, mientras en la civilización griega se crea un espacio público abierto a los ciudadanos conocido con el nombre de plaza publica o ágora, en donde los hombres ciudadanos se entregan totalmente al cuidado y la defensa de los intereses públicos, generando un sentido de participación en donde cada uno en condiciones iguales interviene en la toma de decisiones de la comunidad, en la sociedad burguesa europea moderna la idea de lo público se relaciona con el surgimiento del Estado democrático liberal de Derecho y "en el que el ámbito de lo público alude a las condiciones y estructuraciones que en una sociedad se dan para mantener y hacer posible la vida en comunidad" (Molina, 2003, p. 50).

En el imaginario popular pesan, sin embargo, una serie de consideraciones inexactas alrededor de lo que constituye y caracteriza "lo público".Estos imaginarios fundamentalmente son dos: "uno en donde se ve 'lo público" como lo relacionado con el Estado, lo cual ignora la fundamental interrelación Estado-sociedad. Por otra parte, suele relacionarse 'lo público' con 'lo colectivo', lo cual deja de lado el hecho de que no todo lo colectivo es público" (p.52).

Para otros autores más recientes, como Habermas, en la democracia no debe existir ningún tipo de enajenación de las voluntades; por tanto, la democracia debe estar caracterizada por un libre proceso comunicativo que posibilite el logro de acuerdos consensuales en la toma de decisiones colectivas, en donde la sociedad civil pasa a ser sociedad política (Eduard y Requejo, 2002). Desde esta perspectiva, podemos observar cómo desde lo público, un espacio de construcción de horizontes colectivos, se logra construir un tipo de democracia incluyente del conjunto de la sociedad en términos de la toma de decisiones colectivas.

Los países latinoamericanos han experimentado el predominio de la democracia representativa desde el fin de las dictaduras militares (especialmente en el cono sur), que marca la dinámica de los años ochenta. Tal dinámica se expresa en la elección popular de una amplia serie de servidores públicos no sólo de carácter nacional sino también local. Sin embargo, dicha representatividad ha estado permeada por grandes crisis de legitimidad expresadas en el descontento ciudadano con respecto a sus representantes, lo que hace necesaria una ampliación de la esfera pública y de un sistema contable apropiado que le permitan al ciudadano ejercer control político y soberanía en el territorio, es decir, los modelos contables deben adaptarse a las nuevas necesidades de información surgidas en el marco de una mayor democratización, y en la ampliación del papel y la corresponsabilidad de los ciudadanos en la gestión de los asuntos del Estado. Este es el modelo de la democracia participativa. 
La contabilidad pública debe ampliarse entonces en el marco de la democracia participativa para que su lenguaje sea accesible a toda la ciudadanía y permita un verdadero control social.

...sobre los recursos públicos (...), porque a diferencia de lo que se pregona por los reformadores, lo privatizado no deja de ser público y en un momento importante el análisis debe recaer sobre lo que ocurre con aquellas actividades que pasan a la esfera del mercado y el impacto que sobre el bienestar social y la distribución de la riqueza tienen dichas actividades (Bautista, 2005, p. 25).

Es necesaria la existencia de esferas públicas en la construcción de democracia, pues es allí donde se hace posible "el encuentro y reconocimiento de la diversidad de perspectivas venidas de la sociedad y en donde se produzcan mundos, decisiones u horizontes en común, o también, lugares diferenciados, gestionados pacíficamente a través de la palabra compartida y visible" (Bonilla, 2004, p. 320). De esta forma, al ser el control ciudadano una de las más importantes instancias en la consolidación de una esfera pública incluyente, es necesario plantear la idea de una contabilidad pública participativa donde se logre configurar un adecuado control sobre los recursos a través de la libre discusión y no desde una perspectiva unilateral justificada mediante una supuesta tecnicidad que trae como consecuencia una separación entre el Estado y la sociedad, un sistema de información útil hacia adentro del Estado, pero poco significativo para promover la ciudadanía activa y participativa.

Por esto, al hablar de democracia, es necesario considerar la relación Estado - recursos públicos - sociedad, entendiendo la contabilidad pública como uno de los espacios públicos fundamentales que relaciona y lleva a la sociedad al Estado por medio del control social. En este sentido, los sistemas de información contable deben, a través de la participación activa en la gestión de dichos recursos públicos, convertirse en herramienta de la sociedad al momento de la realización de control político y fiscal, la definición, ejecución y evaluación de políticas públicas y la toma de decisiones. Como parte de la solución a esta problemática se podría plantear que es necesario otorgarle a los individuos participación en la gestión y control de los recursos públicos para que el individuo y la sociedad logren desde sus realidades propias definir y decidir sobre la más adecuada asignación de los recursos.

Es pertinente plantear la idea de que el poder estatal se legitima en la definición de la contabilidad pública. Por tanto, para que el poder estatal sea realmente legítimo, necesita de una contabilidad pública que parta del reconocimiento de las diferentes perspectivas sociales. 
ACTIVOS | REVISTA DE LA FaCULTAD DE CONTADURía PÚBlica

Es necesaria la teoría del interés común en la determinación del interés publico (Bonilla, 2004, p. 404), lo cual tiene que ver con la capacidad de detectar intereses comunes determinados de manera pragmática, sobre la base de la capacidad de identificar diversos "reclamos de interés público". Por tanto, se hace necesaria una política contable con respecto a la definición, manejo e implementación de los recursos públicos.

Para buscar los fundamentos de la democracia es necesario remitirnos a la antigua Grecia. Los griegos concebían dicha idea de formas particulares; por ejemplo, para Aristóteles, la democracia era una de las formas corruptas de gobierno, ya que se refería al gobierno de los muchos en beneficio de ellos mismos. Por el contrario, la República hacía referencia al gobierno ejercido por los muchos en provecho del interés de la comunidad (Eduard y Requejo, 2002, p. 25).

Siglos después, en Roma, se retoma el concepto griego aristotélico y se operativiza a través de un

...complejo mecanismo de distribución de poderes y funciones que reservaba la dirección real del gobierno al pequeño grupo patricio del Senado, pero admitía que un número mas numeroso de individuos, los plebeyos, gozaran así mismo de la condición de miembros de la República y estuvieran representados mediante los tribunos de la plebe (p. 28).

De esta forma, el carácter representativo de la democracia moderna se empieza a gestar. Aparece entonces la perspectiva de la democracia moderna, la cual, a diferencia de la democracia griega que relacionaba la democracia y la república con un deber con la comunidad, tiene que ver con la relación entre Estado y Sociedad (p. 29). Las revoluciones francesa y norteamericana inauguraron políticamente la era de las constituciones, que fueron pactos explícitos que legitimaron la voluntad popular como la fuente de poder, de la estructura democrática del Estado y de las formas representativas de gobierno (Pérez, 2001, p. 23-24).

Sin embargo, los tres principios de la revolución francesa (fraternidad, igualdad y libertad) que hacen parte de la lógica del Estado moderno fueron desintegrados en el proceso histórico que llevó al Estado neoliberal: la religión (especialmente el cristianismo) se apropio de la fraternidad, el sistema socialista acogió la igualdad (que se volvió igualitarismo) y el sistema capitalista tomó como bandera la libertad. El derrumbe de los regímenes autoritarios y la caída del Muro de Berlín crearon un mundo en donde la democracia liberal se 
impuso como la forma normal y superior de organización política, cuyo aspecto económico está representado por la economía de mercado (Touraine, 1995, p. 15).

En Latinoamérica, esto ha conducido a que se viva una democracia de carácter más formal que real, en donde históricamente se ha excluido su característica esencial: la participación de los ciudadanos en la toma de decisiones que afectan los intereses colectivos (públicos). A pesar de los espacios abiertos por algunas constituciones en América Latina, aún prevalece la reducción del ejercicio democrático a la del ejercicio del derecho a elegir los representantes.

Encontramos entonces que la democracia en América Latina favorece unos intereses privados de orden económico a través de una estructura política, en detrimento de los intereses y necesidades públicas de unas mayorías. Esta separación hace que dicha democracia no sea real ni efectiva. Por tanto, y paradójicamente, se requiere ir al ámbito privado para favorecer su integración con el ámbito público:

...no termina en la esfera pública el mundo de la democracia. Esta no puede entenderse sin lo privado, de tal forma que ella -la democracia- no puede ser comprendida sin la "esfera privada". Formas de construcción del poder político sacadas de conocimiento, juicio y acción común de la sociedad, de la esfera pública, influyen en la orientación del poder político, en tres sentidos básicos: desde una concepción sustantiva de la democracia y de democratización, limita la posibilidad de realizar acciones tendientes a la equidad y la justicia social del conjunto de la sociedad, por generar en privado arreglos que benefician a un segmento particular de la sociedad en detrimento de un conjunto general (Molina, 2005, p. 4).

Corresponde así al Estado gobernar a favor de todos y no de un segmento de la sociedad, lo cual le exige apoyar la inclusión de las distintas esferas públicas en debate. Por tanto, "hay democracia cuando existe una sociedad abierta en la que la relación entre gobernantes y gobernados es entendida en el sentido de que el Estado está al servicio de los ciudadanos y no los ciudadanos al servicio del Estado, en la cual el gobierno existe para el pueblo y no viceversa" (Sartori, 1995, p. 24). Lo anterior nos lleva a plantear que para experimentar una democracia plena en Latinoamérica, hay que partir del ciudadano mismo, de la persona como sujeto y actor de lo colectivo. Es necesario admitir "que no hay democracia sin ciudadanía y que no hay ciudadanía sin acuerdo, no sólo sobre procedimientos e instituciones, sino también sobre contenidos" (Touraine, 1995, p. 330). 
ACTIVOS | REVISTA DE LA FaCULTAD DE CONTADURía PÚBlica

Para llegar al ciudadano es necesario trascender la dimensión meramente política de la democracia e ir adonde él se construye como persona:

...es por lo bajo y no por lo alto como hoy en día hay que apartarse de una concepción puramente política de la democracia. Más aún que la creación de una sociedad política justa o que la abolición de todas las formas de dominación y explotación, el objetivo principal de la democracia debe ser permitir a los individuos, a los grupos y a las colectividades convertirse en sujetos libres, productores de su historia, capaces de unir en su acción el universalismo de la razón y la particularidad de una identidad personal y colectiva (Touraine, 1995, p. 275).

\section{La participación como mecanismo de construcción de lo público}

Según Bobbio, "las sociedades modernas buscan activamente los mejores medios para transitar hacia un modelo de organización política en el que la democracia formal se vuelve más real" (Bobbio, 1986). En el caso Latinoamericano, a partir de la década de los noventa se abrieron mayores posibilidades para prácticas participativas en diferentes ámbitos de la vida nacional. Es así como se parte de una idea de participación en donde los ciudadanos inciden en la toma de decisiones de forma directa (Eduard y Requejo, 2002, p. 63). En este sentido, es posible lograr una construcción de lo público desde una dinámica participativa de los individuos que permita alcanzar una verdadera inclusión social.

El sistema de información contable permite crear esferas públicas en donde el ciudadano es quien se ocupa de las cuestiones públicas y no se restringe a la atención de asuntos meramente privados. Por otra parte, es él quien sabe que la deliberación es el procedimiento más adecuado para abordar dichos asuntos. Por esta razón, la información contable y su ejecución deben polemizarse en el conjunto de la sociedad con objeto de identificar realmente cuáles son los actores y sus intereses.

El ciudadano debe participar e involucrarse con autonomía y crítica en las cuestiones públicas y sobretodo en el ámbito de lo contable, ya que son estas acciones las que directamente le afectan positiva o negativamente en su proyecto de vida. Este mecanismo le permitirá tener alguna incidencia real en la solución de sus problemas a partir del control social verdadero sobre los recursos públicos. Es pertinente aclarar que existe una ciudadanía que 
participa o actúa en la esfera pública con el consentimiento y el respaldo del Estado. Por esta razón, la ciudadanía se permite intervenir y debatir, sobre la base de planteamientos, normas y mecanismos establecidos por el Estado.

\section{Lo público y el sistema de información contable con base en el Manual de Estadísticas de Finanzas Públicas 2001}

Desde la década de los noventa estamos en presencia de un fuerte proceso de internacionalización de las normas contables, tanto a nivel privado como a nivel del Estado y sus instituciones. Los primeros intentos por construir un sistema de información comparable en materia de contabilidad fiscal surgidos en los años setenta dan fruto en 1986, cuando se presentan los primeros avances materializados en el Manual de Finanzas Públicas (versión 5), que representa alcances importantes en materia fiscal y que hace profundas revisiones a los conceptos contables que habían sido hasta el momento el eje central del sistema de estadísticas de las finanzas públicas.

Estos cambios serán muchísimo más profundos con la versión 6 del manual, publicada en el año 2001 y que construye una propuesta alrededor de la constitución de todo un sistema de contabilidad que atienda al principio de valoración por causación, lo cual implica unos cambios enormes en los sistemas de contabilidad fiscal. El Manual de Estadísticas de las Finanzas Públicas (versión 6) está basado en el Sistema de Cuentas Nacionales (SCN) de 1993, en el sistema de estadísticas de balanza de pagos y en el sistema de estadísticas monetarias y financieras con los cuales guarda correspondencia. La aplicación prácticamente universal de estas normas muestra un fuerte proceso de internacionalización de la norma contable para el sector público con el objetivo de permitir la comparación del desempeño financiero y fiscal de los diferentes países socios del FMI, como también la toma de decisiones sobre los momentos en que debe hacerse la intervención discrecional que establece el FMI en cumplimiento de sus mandatos institucionales.

Se considera que los conceptos utilizados en el Manual de Estadísticas de Finanzas Públicas son válidos internacionalmente. Esto es bastante discutible, en la medida en que los contextos de revelación contable no son los mismos en las diferentes regiones y menos aún entre países al interior de las regiones. La aplicación de las normas no permitiría un análisis del contexto de cada país, considerándose así que el manual puede ser adoptado por cualquier economía. No obstante, se han presentado diferencias entre los países al momento de adoptarse el manual, que resulta poco pertinente para las realidades espe- 
ACTIVOS | REVISTA DE LA FaCULTAD DE CONTADURía PÚBlica

cíficas de cada nación. Varias de estas diferencias no son solamente conceptuales, sino resistencias a los efectos económicos, políticos y sociales que resultan de efectos de la aplicación de conceptos contenidos en el manual.

En este punto, es importante afirmar que el carácter homogeneizante del manual no permite la construcción de un sistema de información autónomo capaz de responder a los intereses y demandas sociales, sino que es otra forma (sutil, por cierto) de introducir esquemas de presentación de las actividades del sector público que están investidas de un determinado grado de ideología. Lo que sostenemos aquí es que las ideas sobre las funciones del Estado expresadas por el FMI encuentran en la representación contable del manual una forma de introducirse en los sistemas políticos y que como consecuencia de ello se alteran las posibilidades de la política pública, niegan la democracia y se ocultan bajo el ropaje de lo público una serie de intereses sociales que no son los de la colectividad sino de un pequeño grupo que así se beneficia de la apariencia pública de sus intereses.

La información estadística proporcionada por la aplicación de las normas contables del manual ha permitido un análisis más amplio y profundo de la política fiscal entre otras cosas porque permite la valorar de la eficacia del gasto frente a objetivos deseados como la reducción de la pobreza y la posibilidad de hacer sostenibles un conjunto determinado de políticas fiscales, que son (por dar un par de ejemplos) los ejes centrales de la economía política promovida por el FMI para algunos de sus países socios.

Por ello, según el FMI, el Manual de Estadísticas de Finanzas Públicas 2001 tiene como finalidad apoyar el análisis fiscal y como objetivo principal "proporcionar un marco conceptual y contable integral adecuado para analizar y evaluar la política fiscal (...) en lo que se refiere al desempeño del sector gobierno general, y en forma más amplia del sector público de cualquier país" (FMI, 2001,p. 1). Sin embargo, analizar y evaluar no son verbos neutrales y mucho menos lo es la regla con la que se analiza y mide, que en este caso es el sistema contable. Por ello el Manual es una herramienta fundamental para enmarcar las posibilidades de la política fiscal. Dado que la información proporcionada por el sistema contable que propone el FMI permite tomar decisiones fiscales, éstas van a ser limitadas por el sistema de información que les da origen.

La estructura contable propuesta considera dos grandes elementos: el sector gobierno general y el sector público. En el primero se encuentran todas las unidades institucionales ${ }^{6}$

6 Según el MEFP 2001, las unidades institucionales se definen como: “entidad económica que tiene capacidad, por derecho propio, de poseer activos, incurrir pasivos y realizar actividades económicas y transacciones con otras entidades" (FMI, 2001, p. 9). 
que realizan principalmente actividades de no mercado, es decir, proveen bienes y servicios gratuitamente o a precios inferiores a los de mercado para la población en general, lo cual supone un control o financiamiento por unidades gubernamentales mediante el cobro de impuestos. Esto es lo que el FMI considera como entidades que cumplen una responsabilidad pública clara y que ofrecen bienes públicos a la ciudadanía; son el núcleo del Estado Mínimo propuesto por la ideología neoliberal.

Por otra parte, una segunda definición contable importante la constituye la agregación de cuentas de las entidades del llamado sector público, la cual está conformada por las denominadas corporaciones públicas ${ }^{7}$ y las unidades del sector del gobierno general. La información que se recopila en estos sectores permite medir el impacto que tienen las actividades de las corporaciones públicas en la política fiscal.

De esta manera, Borja (2003, p. 5) expone los principales sectores de lo que se considera como el sector público en el Manual de Estadísticas de Finanzas Públicas. A continuación se observan en la Figura 1 los criterios de medición de la contabilidad fiscal propuestos por Borja.

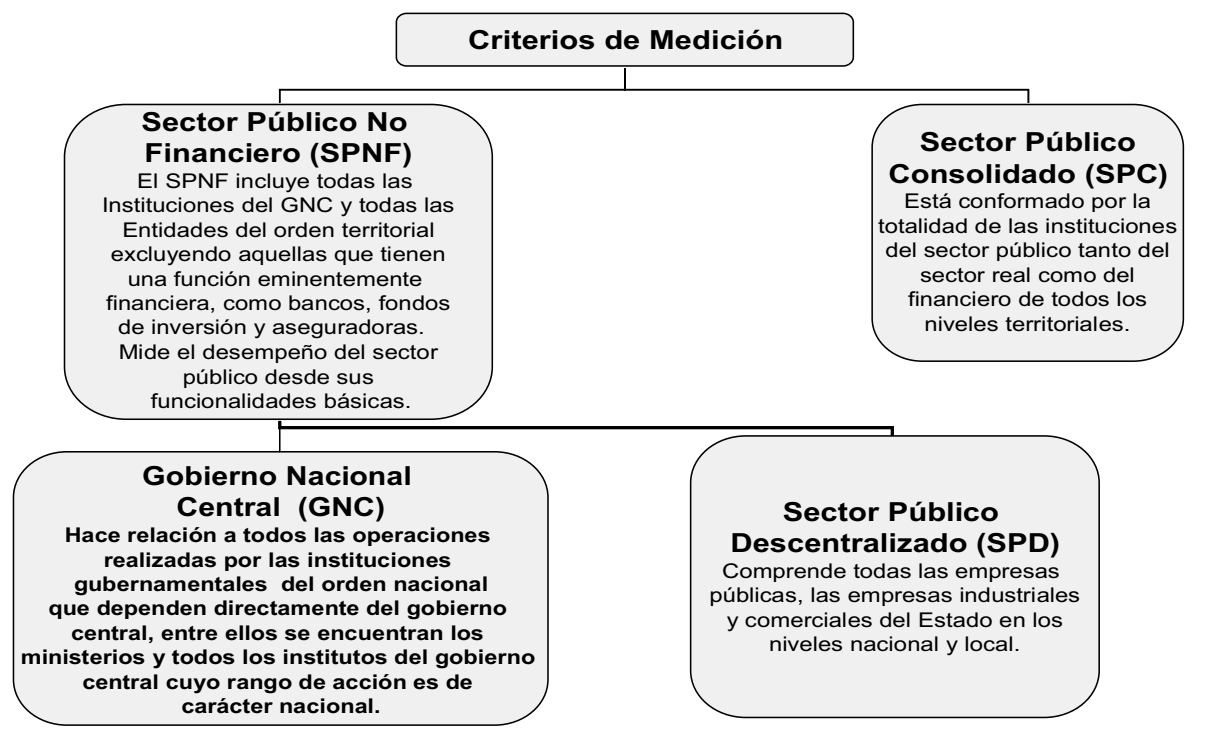

Fuente: Borja (2003).

Figura 1. Criterios de medición de la contabilidad fiscal

7 Definidas según el MEFP (Borja, 2003, p. 9) como: “entidades jurídicas, creadas con el fin de producir bienes o servicios para el mercado (...) que produzcan bienes y servicios para el mercado y sean fuente de utilidades u otra ganancia financiera para sus propietarios". 
ACTIVOS | REVISTA DE LA FaCUlTAD DE CONTADURÍa PÚblica

Aquí encontramos dos serios problemas planteados por el manual. En primer lugar, la definición de gobierno usada por el FMI es aquella que permite introducir en el sistema contable la idea del Estado Mínimo, aunque aquí se conceptualiza que son bienes públicos solamente aquellos que el FMI considera que no son bienes de mercado, sin tener en cuenta que lo público no es solamente un problema de definiciones económicas sino ante todo un problema político y de definiciones profundas de la estructura social. El segundo elemento problemático es que la definición que de lo público hace el FMI limita la estructura de bienes públicos solamente a aquellos que son ofertados por las unidades de gobierno, mientras que los bienes ofertados por las llamadas corporaciones públicas son bienes que: 1 . No son gratuitos; 2 . Su oferta se hace en condiciones de mercado; y 3. Implican una lógica de beneficio privado para la organización, la cual implica también una lógica de control en interés de la maximización del beneficio financiero para quien controla la organización.

De esta manera, el sistema contable introduce en la dinámica de representación unas definiciones conceptuales que reproducen la idea de que el Estado tiene implícitas dos tipos de racionalidades: una racionalidad plenamente pública (unidades gubernamentales) en donde los bienes se ofrecen de manera "gratuita", y se financian a través de la distribución de la carga tributaria; y otra racionalidad de mercado, en (corporaciones públicas) donde los bienes ya no son de carácter público sino que están sometidos a la lógica de la utilidad o ganancia privada y, lo más importante, que constituyen el principal frente de privatizaciones.

La construcción patrimonialista en la conceptualización de los espacios públicos que subyace las definiciones centrales del MEFP, ignora algo que hemos mostrado en la primera parte del texto: que lo público es ante todo un problema político, que está en la base de la construcción de una democracia, y que las democracias no solamente requieren de votaciones, es decir, accesos libres a la representación electoral, sino también de acceso al control de los recursos que garantizan la garantía del sistema de los derechos constitucionales establecidos. Cuando lo público se adscribe a una lógica de propiedad, más que a la acción que busca desempeñar en términos de beneficio social, cuando un hospital o una escuela pueden ser definidos como corporaciones, es decir, como empresas productoras de utilidad, un cambio de enorme trascendencia se ha operativizado en el espacio de lo público.

De otro lado, el enfoque patrimonial del MEFP deja de lado un problema enorme en la administración de lo público: dado que la línea público-privado no está representada en el sistema de cuentas fiscales, porque por definición el ámbito de lo privado es diferente al del Estado, hay un sinnúmero de procesos económicos que no están registrados en las cuentas fiscales, pero que tienen un impacto real o potencial en las mismas. Un ejemplo 
que ilustra mejor este fenómeno es el referido a los potenciales efectos que la gestión de los fondos privados de pensiones pueden tener en las finanzas del Estado, especialmente en aquellos países donde se garantiza por parte del Estado una pensión mínima (como en el caso colombiano).

Por otra parte, el MEFP al definir los conceptos de ingresos y gastos en relación con su impacto patrimonial en las cuentas públicas, termina haciendo una consideración fundamental acerca del impacto del déficit fiscal que se corresponde más al impacto que ocurre en la contabilidad privada. Veamos en detalle este argumento.

El manual define como ingreso el "aumento del patrimonio neto como resultado de una transacción” (FMI, 2001, p. 53) y categoriza estos ingresos como provenientes de “... cuatro fuentes principales de ingreso (...): los impuestos y otras transferencias obligatorias impuestas por unidades del gobierno, las rentas derivadas de la propiedad de activos, las ventas de bienes y servicios, y las transferencias voluntarias recibidas de otras unidades" (p. 54). En otras palabras, los ingresos son el incremento del patrimonio derivado de un acuerdo entre el Estado y la sociedad, ya sean impuestos, donaciones, rentas, ventas de bienes y servicios, dando así una clasificación de los diferentes tipos de ingresos públicos.

Por otra parte, el MEFP define como gasto la

...disminución del patrimonio neto como resultado de una transacción. Los gobiernos tienen dos funciones económicas generales: asumir la responsabilidad de proveer ciertos bienes y servicios a la comunidad sobre una base no de mercado y redistribuir el ingreso y la riqueza mediante pagos de transferencia (p. 71).

Es decir, el patrimonio público se reduce cuando se utiliza para suministrar ciertos bienes y servicios "públicos", siendo para ello necesario identificar el tipo de gasto que se realizó para cumplir con dicho objetivo -clasificación económica-, además del propósito que motivó el gasto -clasificación funcional-, o el impacto de dicho gasto en el crecimiento del capital de la economía -clasificación por tipos de capital-.

Ahora bien, en el caso de que los ingresos sean menores que los gastos (déficit fiscal), lo que se encuentra es una disminución neta del capital público, con lo cual parece haber aquí un razonamiento contable que pretende llevar a las economías fiscales a situaciones de supéravit neto, pues desde esta perspectiva parece que las consecuencias sobre el déficit 
ACTIVOS | REVISTA DE LA FaCULTAD DE CONTADURía PÚBlica

y el supéravit son iguales o equivalentes a las que ocurren en la contabilidad privada con los conceptos de pérdida y utilidad.

Esto conceptualmente es un exabrupto, inicialmente porque comparar las funciones de ingreso y gasto con sus equivalencias en la creación del patrimonio público, sólo es posible si se entiende por patrimonio público un conjunto de recursos financieros que pertenecen al Estado. Pero teóricamente el Estado no es solamente una entidad económica, su función principal es la de garantizar la gobernabilidad social, entendiendo esta como "la capacidad política del gobierno de intermediar intereses, garantizar la legitimidad y gobernar" (Bresser Pereria, 2000,p. 111), lo cual logra por medio de "la conformación de instituciones con suficientes habilidades para mediar entre los distintos intereses que se juegan en el marco de las dinámicas sociales cambiantes y las relaciones de estas con el Gobierno” (p. 132).

Lo anterior lleva a una curiosa conclusión: al ser el gasto social una mera disminución del patrimonio neto que, por ende, es recomendable reducir, el Estado ve amenazada su legitimidad pues no existe una preocupación por los intereses sociales y por el buen gobierno de los asuntos públicos, sino solamente se persigue el objetivo de estabilización y equilibrio fiscal. No estamos defendiendo aquí una política ampliamente deficitaria per se, pero sí queremos señalar que el déficit fiscal puede tener efectos beneficiosos en el corto y largo plazo, e incluso es un mecanismo de control de las tensiones políticas, y además que junto con la política de ingresos se constituyen en herramientas eficaces para mejorar la distribución del ingreso en la sociedad.

Por tanto, la definición de patrimonio público no puede estar restringida a una mera variable financiera, sino que contablemente debe revelar toda la compleja serie de acontecimientos que contribuyen a la formación de ese patrimonio: la legitimidad del Estado (el principal de ellos), el cumplimiento de las funciones sociales para las cuales fue creado, la generación de riqueza y valor agregado para las organizaciones privadas, el logro de un entorno de confianza y seguridad en la sociedad, etc. Estos son factores reales que constituyen el patrimonio estatal y no solamente las abstracciones financieras surgidas de la interrelación de sus variables fiscales.

En este sentido, la afirmación según la cual, la "elaboración del presupuesto público se traduce en un acto político" (Giraldo, 2001, p. 58), implica definiciones fundamentales sobre quién aporta los recursos (impuestos) y a quién va a beneficiar el gasto público. El carácter político del presupuesto requiere por tanto la participación de “todos" en la definición de las preferencias sobre el destino de los recursos públicos, bajo la racionalidad de que las 
finanzas públicas construyen un patrimonio público que no es solamente privativo del Estado, sino que se traduce en una serie de condiciones de bienestar social. A pesar de ello, el contexto y las dinámicas globales señalan que "la discusión de los asuntos presupuestales se hace en función del programa macroeconómico del país, que se basa en los postulados de la programación financiera del FMI" (Giraldo, 2001, p. 95). Es decir, que el sistema contable público internaliza la propuesta de una dinámica de equilibrios financieros, antes que una dinámica de armonías sociales que es lo que nosotros consideramos como la constructora del patrimonio público.

La contabilidad pública entonces debe avanzar en la superación de esta restringida visión patrimonialista, vincular las representaciones políticas de la sociedad como parte de las representaciones contables y abandonar la similitud que se le quiere imprimir con los sistemas de contabilidad privada, que finalmente terminan por incentivar el ajuste fiscal, como también buscar la obtención de "utilidades" o supéravits, valorando el patrimonio financiero del Estado, pero sin medir los impactos de estas políticas en el patrimonio público.

\section{Conclusiones}

- La homogenización del sistema de información contable es producto del nuevo orden mundial caracterizado por el fenómeno de la globalización, en el cual la búsqueda de nuevos mercados por parte de los grandes capitales obliga a la estandarización de estructuras económicas.

- En Latinoamérica, el cambio de paradigma económico reconfigura al Estado pasando de un modelo intervencionista, en donde el Estado es ente activo en las dinámicas económicas, a uno gendarme y regulacionista en donde prevalecen las políticas económicas de los organismos supranacionales.

- En la definición de los sistemas de información contable se desconoce la amplitud del concepto de lo público. Éste se reduce al aparato estatal que fija sus objetivos con relación a las utilidades patrimoniales y no a los beneficios sociales.

- La contabilidad pública es un instrumento relevante para ejercer control sobre los recursos públicos. De esta forma, es necesario que dicha contabilidad sea accesible al conjunto de la sociedad, permitiéndose así la construcción de una verdadera democracia.

- La definición actual de ingresos y gastos públicos, y la forma de medición del déficit fiscal determinada por el Manual de Estadísticas de Finanzas Públicas 2001, restringe la labor social que debe desarrollar el Estado contradiciendo la concepción que emana del Estado Social de Derecho. 
ACTIVOS | REVISTA DE LA FACULTAD DE CONTADURía PÚBLICA

\section{Referencias}

Banco Mundial.(1995). El Estado en un mundo en transformación - informe mundial sobre el desarrollo. Washington: Banco Mundial.

Bautista, J. (2004). Sobre el ámbito de la contabilidad pública: avances preliminares. Ponencia presentada en el VI Simposium Internacional de Investigación Contable (CCINCO). Universidad de Manizales, agosto de 2005.

Bautista, J. (2008). Notas de clase de Finanzas públicas. Escuela Superior de Administración Pública. Documento sin publicar.

Bernal Medina, J.A. (1999). Construir ciudadanía para una justicia social. Herramientas, $8,(62)$.

Berry, A. (2004). “Focalización y subsidios: ¿por la demanda o por la oferta?” En: Laguado Duca, A. C. La política social desde la constitución de 1991 ¿una década perdida? Bogotá: Colección CES.

Bobbio, N. (1986). El futuro de la democracia. México: Fondo de Cultura Económica.

Borja,W.A.(2003). Política fiscal: ¿qué es y para qué sirve? Bogotá. Documento realizado para el Seminario Interno de la Unidad de Trabajo Legislativo.

Bresser Pereira,L.C. (2000). "Reforma del Estado en los años noventa: lógica y mecanismos de control". En: Carrizo, F. Democracia en déficit. Washington: BID.

Comisión Económica para América Latina y el Caribe - CEPAL. (1998). El pacto fiscal: fortalezas, debilidades, desafíos. Santiago de Chile: CEPAL.

Declaración del XXI congreso de la internacional socialista o declaración de Paris, (1999).En: Roll, D. (comp.).Humanizar la globalización. Estado, economía y cultura en el nuevo milenio. Bogotá: CEREC.

Eduard \& Requejo, F.(2002). Democracia: las razones de un sueño que genera monstruos. Bogotá: Universidad Nacional de Colombia - Facultad de Derecho y Ciencias Políticas. 
Fondo Monetario Internacional - FMI. (2001). Manual de estadísticas de las finanzas públicas. Recuperado el 9 de agosto de 2009 desde http://www.imf.org

Giraldo, C. (comp.).(2003). El rescate de lo público, poder financiero y derechos sociales. Bogotá: Ediciones Desde Abajo.

Giraldo, C. (2006). Protección o desprotección social. Bogotá: Ediciones Desde Abajo.

Giraldo, C. (2008). Finanzas públicas en América Latina: la economía política (2a ed.). Bogotá: Ediciones Desde Abajo.

Held, D. (1997). “El desarrollo del Estado-nación y la consolidación de la democracia”. En La democracia y el orden global. Barcelona: Paidós.

Lozano Ayala, A. (2005). "Debates sobre lo público". En: Hacia una definición de lo público. Bogotá: Universidad Nacional de Colombia, Facultad de Ciencias Políticas y Sociales - ESAP.

Molina, J. (2003). "La pregunta por lo público”. En: El rescate de lo público. Poder financiero y derechos sociales. Bogotá: Ediciones Desde Abajo.

Molina, J. (2005). Democracia en Colombia y construcción de lo público: balance de una década. Bogotá: ESAP.

Santos, R. (2002). Medios, calidad y responsabilidad social. Conferencia dictada en el marco de televisión pública: del consumidor al ciudadano. Bogotá, noviembre.

Sartori, G. (1995). ¿Qué es la democracia? México: Fondo de Cultura Económica.

Touraine, A. (1995). ¿Qué es la democracia? México: Fondo de Cultura Económica.

Touraine, A. (2005). El papel social del Estado en el mundo de la globalización. En: Nova Et Vetera, 55. Bogotá: ESAP.

Pérez, T. (2001). Convivencia solidaria y democrática. Ismac.

Rawls, J. (2001). Teoría de la justicia. México: Fondo de Cultura Económica. 
ACTIVOS | REVISTA dE LA FACULTAD DE CONTADURÍA PÚblica

Vargas Hernández,J. (2004).“Los desafíos de la administración pública en América Latina”. En: Estado, gobierno, gestión pública. Revista Chilena de Administración Pública.

Zapata Barrero, R. (1996). Hacia una teoría normativa de la ciudadanía democrática. Revista Foro, (28). 